\title{
Demand Side Financing and Healthcare Seeking of Pregnant Women
}

Tanzila Rahman

Lecturer, Department of Pharmacology, Dhaka Dental College.

Corresponding Author: Tanzila Rahman, Lecturer, Department of Pharmacology, Dhaka Dental College.

Received Date: 28 October 2021 | Accepted Date: 25 November 2021 | Published Date: 04 January 2022

Citation: T Rahman. (2022). Demand Side Financing and Healthcare Seeking of Pregnant Women. Journal of Clinical and Laboratory Research. 5(1); DOI:10.31579/2768-0487/058

Copyright: ( 2022 Tanzila Rahman. This is an open-access article distributed under the terms of the Creative Commons Attribution License, which permits unrestricted use, distribution, and reproduction in any medium, provided the original author and source are credited.

\begin{abstract}
Demand-side financing (DSF) scheme is popularly known as the maternal health voucher program, which is launched in many developing countries of the world including Bangladesh as an intervention of developing overall health status. Maternal mortality ratio is a strong indicator of health profile of any country and pregnant women are prone to fall vulnerable situation. This review was aimed to find gap/missing of existing literature in order to make foundation of new research on healthcare seeking of pregnant women along with financing coverage. After repeated critical review of number original articles, some gaps have been found. Almost every article they focused on outcome and mildly highlighted input variables but did not consider all possible variables and missed to show interlink between those variables.
\end{abstract}

Key words: pregnant women; healthcare; ANC

\section{Introduction}

Demand side financing (DSF) with a diversified design have been introduced to increase the health service utilization by offsetting some financial costs for users. Bangladesh Government had launched this program in 2007 with the mission of reducing maternal mortality ratio and infant mortality ratio by promoting ante natal care, facilitated delivery and post natal care. A voucher scheme was introduced for lowincome, pregnant women to enhance the utilization of maternal and child health services among the poorest women for lowering financial barriers to accessing institutional delivery care. Kenya Cambodia, Mozambique, Uganda, Ethiopia Mexico introduced DSF program. In Indian subcontinent Bangladesh, India, Pakistan and Nepal introduced DSF program. This review emphasizes on pregnancy healthcare and financial coverage.

\section{Studied literatures}

With the ultimate goal of reducing maternal and neonatal mortality, many countries have recently adopted innovative financing mechanisms to encourage the use of professional maternal health services. Underutilization of health facilities is common in developing countries and over the past few years policy makers have been revising existing policies to address this persistent challenge. Available evidence indicates that vouchers do improve service utilization among the target populations [1]. In a study conducted in India revealed that out of 426 women Only $25.3 \%$ of women gave birth in health institutions for their recent birth with the help of health professionals while majority $(74.7 \%)$ of women gave birth at home without the help of health professionals. Rural women were less likely to use institutional delivery, $20.9 \%$, as compared to urban women, $35.9 \%$ [21]. Globally, while 86 per cent of pregnant women access antenatal care with skilled health personnel at least once, only two in three (65 per cent) receive at least four antenatal visits. In regions with the highest rates of maternal mortality, such as sub-Saharan Africa and South Asia, even fewer women received at least four antenatal visits 52 per cent and 49 per cent, respectively [19]. Improvements in the coverage of the proportion of births attended by qualified healthcare workers and their care may have contributed to maternal mortality decreases between 1990 and 2015.Nonetheless, the approximate birth coverage attended by trained health workers between 2012 and 2017 indicates disparity between WHO regions as only 59\% of births in the sub-Saharan Africa region. Despite substantial progress over the last two decades, inadequate or non-existent care during pregnancy and delivery was largely responsible for the annual deaths of an estimated 303,000 mothers and 2.5 million newborns in the first month of life in 2017. Indeed, roughly three-quarters of all maternal deaths take place during delivery and in the immediate postpartum period [19]. Full ANC utilization in India was inadequate and inequitable. Although half of the women did not receive the minimum recommended ANC visits, the utilization of TT immunization was almost universal. In India, $21 \%$ of pregnant women utilized full ANC, ranging from $2.3-65.9 \%$ across states. Overall, $51.6 \%$ had 4 or more ANC visits and $91.1 \%$ had one or more doses of tetanus toxoid. Full ANC utilization was inequitable across place of residence, caste and maternal education (Kumar G et al., 2019). In Pakistan, there has been a 
substantial increase in antenatal care coverage over the last two decades, with the percent of women making at least one ANC visit during pregnancy increasing from $26 \%$ in $1990-91$ to $78 \%$ in 2012-13. However, Demographic Health Survey showed that among women who received ANC, only $17 \%$ received six elements of care that should be provided during an ANC visit. By 2012-13, only $28 \%$ of women who had had an ANC check-up received these six elements of care. Pregnant women receiving antenatal care in Pakistan was reported at $86.2 \%$ in 2018 (World Bank Report, 2018). Antenatal care coverage in Sri Lanka is currently $99 \%$ and is provided by consultant obstetricians and gynecologists in tertiary care centers and by public health midwives and medical officers of health in the primary health care centers. The coverage of ANC and delivery care in Myanmar has been improved. The ANC coverage was increased from $63.1 \%$ in 2005 to $86.1 \%$ in 2016. Likewise, the delivery by SBA was increased from $64.4 \%$ in 2009 to $78.4 \%$ in 2016 [12]. Antenatal care offers the opportunity to connect women to the health system, and improve maternal and child health outcomes through prevention, health promotion and treatment during pregnancy. ANC can increase access to and chances of using a skilled attendant at birth around labor and delivery - which is when most maternal and newborn deaths occur - through a birth and emergency preparedness plan. In rural areas, 18 percent of women made at least 4 antenatal care (ANC) visits compared to 43 percent in urban areas. Coverage of skilled attendance at birth is 36 percent in rural areas, compared to 61 percent in urban areas. 47 percent of newborns in rural areas receive PNC within two days after birth, compared to 69 percent in urban [19]. One of the important barriers in reducing maternal mortality is the low utilization of maternal health services provided by the public health system. The use of maternal health services is essential for preventing maternal mortality and morbidity. Factors affecting the maternal health services were used worldwide research material. Delay in seeking medical care results from many factors which includes socio economic and cultural factors. These include traditional culture social norms and religious belief, lack of knowledge about the benefits of maternal health and danger signs of pregnancy, low perception of risk and complication previous experience with the health system, lack of decision making power of women and perceived cost of services and other related expenses. Demand side financing mechanisms are intervention that uses financial incentives on demand side to encourage a population receiving specific services they need. Demand side financing projects are now implemented in many developing countries to reduce the financial burden of the specific group of population, especially poor [11]. In recent years DSF become more popular among governments of many countries, especially in low and middle income countries. In a competitive market, introducing DSF leads to give quality of service and welfare and reduce government expenditure. But in noncompetitive market the effects may be opposite. The advantage of DSF is that consumers may choose the supplies, the quality composition of package. As DSF influences suppliers to compete for the consumer's budget, it stimulates suppliers to provide high quality and low priced goods and services. A potential disadvantage of DSF is that higher or uncertain cost for the government, misuse of budget and money ending up in the hands of suppliers without proper monitoring [18]. In middle and low income Countries, it is well documented that financial costs for transport and treatment and opportunity cost of receiving care are main barriers, for uptake of health care services. The concept of DSF in health originated in response to developing countries' felt need to improve access \& utilization of health care services, particularly among the poor. The poor and vulnerable section of the population deprived of basic health care services, like family planning, maternal and child health, immunization etc [17]. In April 2012, in Washington D.C. USA, the United states Agency for International development convened an evidence summit, the goal of the summit was to review the knowledge $\&$ population on the utilization of financial incentives of health care by multidisciplinary expert review of literature. The goal was to provide recommendation to the donors \& government of low \& middle income countries on evidence informed practice policies and strategies for financial incentives. The Evidence Summit under took a systematic review of five financial strategies. Evidences suggests that voucher program can serve population by keeping the management cost low, improvement of quality of service and address population of bottom two quintiles [2]. The Global literature contains many example of demand side financing (DSF) with different terminologies. DSF can be consumer-led (Vouchers, Cash transfer's, Tax rebates) or provider-led (capitation payment, referral vouchers) and can be provided before or after service utilization. The most commonly used DSF mechanism is vouchers, which is defined as a token that can be used in exchange of specific range of specific goods or services. Vouchers schemes are usually designed for a target group of population, usually for poor and non-privileged people (Ensor T, 2004). Health vouchers encourages the use of under-consumed services like family planning treatment of infectious disease, immunization, maternal and child health care, mental health care by subsidizing (fully or partially) health care costs [5]. Another often-mentioned mechanism is output base aid (OBA) which is a combination of both consumers led \& provides led DSF. These are also called vouchers and accreditation Strategies for health services which put emphasis not only consumer incentives but also attempt to ensure quality services by enforcing performance based contracts with facilities [17].Such initiative have been launched in Bangladesh, India, Kenya, Nicaragua, Taiwan (province of China) and Uganda. These schemes are seen as more effectives because they allow for competition among providers rather than single window provides access. Output based aid through vouchers is now an important strategy for donors combating to improve the effectiveness of aid. The World Bank has been the most active participant in OBA. [17]. Mozambique is Southern African country where maternal mortality is very high. Each day 800 women die due to pregnancy related complication. MMR of the county in 2017 was 289/Lac live birth. Infant mortality rate (IMR) in 2017 was 53.3 deaths / 1000 live birth. Health service coverage is however very low. 54\% women give birth at home and there are only 2.2 health centers for 5 lacs population which provide emergency obstetric and neonatal care. But WHO recommends 5 health centers for 5 Lac inhabitants. As a result, MMR in Mozambique remains high. Low institutional birth rate was labeled as the prime cause. In this situation the country launched baby package intervention of USD 5.50 in one district (Cabo Delago) in June 2010. The intervention had dramatic increases, almost twice as likely to have an institutional birth rate in that district, so, the DSF program proved as a successful program in the intervention district [13]. Uganda is one of the sub-Saharan African countries that did not achieve the MDG- 5 by 2015 [20].In this context, the country implemented different innovative approaches that target both demand and supply side. These included conditional cash transfer, clean birth kit and transport voucher. The Ministry of health introduced the DSF program in 2003. Transport voucher were given to the pregnant women while attending ANC in Acuba-sub country. The baby kit was distributed in Nagi-sub-country among the women who delivered at health center before being discharged. The number of clients attending the four antenatal care visits, the number of intuitional deliveries showed a greater increase after the starting of intervention. The number of postnatal care also rose sharply. According to DID analysis, 30\% of the expected deliveries in the intervention area was associated with the introduction of Baby-kit. On the contrary, the transport voucher had a greater effect on utilization of maternal health care services than that of baby-kit intervention. The service coverage of four ANC visits, institutional deliveries and PNC in the transport voucher attributed area were $60 \%, 42.9 \%$ and $49.2 \%$ respectively. So, it is evident that combination of both interventions will lead to positive synergistic effects on service utilization [14]. The maternal mortality ratio of Cambodia is the highest among South and 
South-East Asia, which is 472 death/100000 live birth. The Cambodia demographic and health survey (2005) showed that $43.8 \%$ of deliveries were assisted by trained health professionals, and $21.5 \%$ occurred in health facility. More than half of women still delivered with a traditional birth attendant at home. (National Institute of Public Health of Cambodia, 2011) Furthermore, institutional delivery is much power among poor women than that of rich. Poor pregnant women have to tackle financial barriers to access the health care services. In Cambodia, Ministry of health with the donor support of Belgian technical Cooperation initiated a vouchers scheme in 2007. Along with the exiting Health equity fund and available evidence suggests that the voucher program effectively improve utilization of maternal healthcare services [5]. One study was conducted after implementation of voucher program in three rural districts of Cambodia. The study evaluated their effectiveness in improving access for poor women to qualified birth attendants in three rural health districts in Cambodia and learn lessons for further improvement The increase was far more substantial than the lack of voucher and HEF schemes in comparable districts. Deliveries in facilities increased sharply from $16.3 \%$ in 2006 to $44.9 \%$ in 2008 following the introduction of voucher and HEF schemes [6]. Maternal mortality ratio in Pakistan is Progress in declining in MMR is very slow. In spite of establishment of well-funded maternal health project, only $39 \%$ of deliveries are attended by skilled birth attendant [11]. A maternal health voucher scheme was launched in Jhang, a rural district of Pakistan which included there ANC visits, a normal delivery combined with PNC visit, a referral for a caesarian section and a postnatal family planning visit. After implementation of the project the ANC visit and institutional deliveries are increased, PNC use increased among poor women in the intervention area [11]. In 2005, Nepal launched Free delivery care policy under the name of MIS which was expanded in 2009 as new name Aama to increase the utilization of maternal health care services. The program included free delivery care services to reduce transport costs providing cash incentives for attending four or more antenatal care visits and for institutional deliveries. After launching the program in 2005, the four antenatal care visits was increased by four times increase compared to when there was no FDC policy. Similarly, institutional deliveries increased by two times after implementation of MIS and increasing five folds after implementation of Aama program [3]. Maternity morality in India is 130/100000 live birth. The Government of India launched Janani Suraksha Yojana (JSY, Safe Motherhood Program), on the principles of DSF through conditional cash transfer for increasing institutional delivery and thereby decrease maternal morbidly and mortality. It provides cash incentives to pregnant women and frontline workers. The scheme became successful in increasing institutional delivery especially in public health institution. DSF has been implemented to improve maternal health, by removing the social, cultural and financial barriers in accessing quality obstetric care. [10]. The study from West Bengal revealed that benefit amount is low and need to increase. Many women had to borrow money to bear the cost of institutional deliveries [15]. The Chiranjeevi Scheme, implemented by the Government of Gujarat, aims at encouraging the BPL families to access institutional delivery at a private hospital. It was estimated that 1.2 million children born every day in Gujrat both at domiciliary and health facility. The maternal mortality ratio is 172/100000 live birth. About 2064 of these mothers die from maternal causes. The primary cause of all these deaths is delivery of child by unskilled birth attendant and the mortality can be avoidable. The Chiranjeevi Scheme provided financial incentives for transport cost and support to the accompanying person for loss of wages. The scheme was launched as pilot project in 2005 and now extended in the whole state. This scheme focuses on institutional delivery, specifically emergency obstetric care for the poor [16]. Voucher, a demand side financing (DSF) instrument is for health care services, introduced in Bangladesh in 2006. The DSF program grants vouchers to pregnant women to receive free antenatal, delivery, and postnatal care service and financial assistance is provided for transportation. Deliveries with skilled service providers are incentivized and providers are reimbursed for their special fund. The Ministry of Health and Family Welfare (MOHFW) of Bangladesh is piloting a maternal health voucher program in 44 upazilas (sub-districts) around the country as part of its Health, Nutrition and Population Sector Program (HNPSP) as a test case for demand side financing. The goal of the program is to increase the use of qualified delivery attendants and ease the monetary prices of delivery. Among the initial 33 upazilas 9 had universal coverage with all the pregnant women receiving the vouchers. In the remaining 24 upazilas, targeting was based on economic status of the beneficiaries. In these upazilas, eligibility was restricted to extremely poor women who owned less than 6,534 sft. of land, whose household earning was less than 3100 BDT per month, who lacked ownership of other productive assets and who was first or second time pregnant (Ministry of Health and Family Welfare Government of the People's Republic of Bangladesh, 2012).The program also intends to encompass non-public and NGO services as potential vendors of maternal care to stimulate competition among carriers to enhance satisfactory of care. In Bangladesh, there are experiences with at least three other voucher programs for maternal health services, although all are small in scale. In Bangladesh, there are experiences with at least three other voucher programs for maternal health services, although all are small in scale. One program implemented by the International Centre for Diarrheal Disease Research, Bangladesh (ICDDR,B) Learning from Demand Side Financing: Bangladesh Scenario is the Community Health Project in Chakaria upazila of Cox's Bazaar district, while another voucher scheme called 'Demand-based Reproductive Health Commodity Project', was jointly piloted by RTM International, ICDDR,B, and the Population Council. Marie Stopes Clinic Society is implementing a voucher scheme, alongside other interventions, in three districts: Shariatpur, Bhola, and Barisal (HEU 2010). Under these voucher programs, women received antenatal care (ANC), post-natal care (PNC) and delivery services free of cost at designated facilities. Demand-based Reproductive Health Commodity Project and Marie Stopes Clinic Society provided transportation voucher to facilitate access to services, however, women did not receive any other cash incentives besides the voucher under any of these projects. All these small scale voucher programs, with financial assistance from development partners, had been successful in increasing use of ANC, PNC and delivery care (Rahman M, 2009).

\section{References}

1. Agha S. (2011). Changes in the proportion of facility-based deliveries and related maternal health services among the poor in rural Jhang, Pakistan: results from a demand-side financing intervention. International Journal for Equity in Health. 10:1:57.

2. Bellows B.W, Conlon C.M, Higgs E.S, Townsend J.W, Nahed M.G, Cavanaugh K, Grainger C.G, Okal J and Gorter A.C. (2013). A Taxonomy and Results from a Comprehensive Review of 28 Maternal Health Voucher Programmes. Journal of Health, Population, and Nutrition. 31(4):1 2-16.

3. Bhatt H, Suresh Tiwari, Ensor T, Dhruba RG, and GavidiaT. (2019). Contribution of Nepal's Free Delivery Care Policies in Improving Utilisation of Maternal Health Services. International Journal of Health Policy and Management. 7(7):645-655.

4. Ensor T. (2004). Consumer-led demand side financing in health and education and its relevance for low and middle income countries. The International Journal of Health Planning and Management. 19(3):267-285.

5. Gorter A, Sandiford P, Rojas Z et al. (2003). Competitive Voucher Schemes for Health. Background Paper, Washington, DC: Central American Health Institute/World Bank. 
6. Ir P, Horemans D, Souk N and Van Damme W. (2010). Using targeted vouchers and health equity funds to improve access to skilled birth attendants for poor women: a case study in three rural health districts in Cambodia. BMC Pregnancy and Childbirth. 10(1).

7. Jacobs B, and Price N. (2005). Improving access for the poorest to public sector health services: insights from Kirivong Operational Health District in Cambodia. Health Policy and Planning. 2(1):27-39.

8. Janssen MCW, Maasland E, Mendys-Kamphorst E. (2013). The Economics of Demand-Side Financing Commissioned by The Dutch Ministry of Economic Affairs SEOR-ECRI.

9. Jacobs B, Ir P, Bigdeli M, Annear P.L. and Van Damme W. (2011). Addressing access barriers to health services: an analytical framework for selecting appropriate interventions in low-income Asian countries. Health Policy and Planning. 27(4):288-300.

10. Khan M, Agrawal P, Hazra A, Dixit A, Bhatnagar I, Ahmad J. and Ahmad, D. (2013). Findings from Learning Phase Baseline Survey, 2013 Maternal and Newborn Behaviors in Rural Uttar Pradesh Health.

11. Kumar G, Choudhary TS, Srivastava A. et al. (2019). Utilisation, equity and determinants of full antenatal care in India: analysis from the National Family Health Survey 4. BMC Pregnancy Childbirth. 19:327.

12. Myint A.N.M, Liabsuetrakul T, Htay T.T. et al. (2018). Inequity in the utilization of antenatal and delivery care in Yangon region, Myanmar: a cross-sectional study. Int J Equity Health. 17:63.

13. Makins A, Ehmer J, Piprek A, Mbofana F, Ross A. and Hobbins M.A. (2019). Demand-side financing in the form of baby packages in Northern Mozambique: Results from an observational study. PLOS ONE. (14):5.
14. Massavon W, Wilunda C, Nannini M, Majwala R.K, Agaro C, De Vivo E, Lochoro P, Putoto G. and Criel B. (2017). Effects of demand-side incentives in improving the utilisation of delivery services in Oyam District in northern Uganda: a quasiexperimental study. BMC Pregnancy and Childbirth. 17:1.

15. Mukhopadhyay D.K, Mukhopadhyay S, Mallik S, Nayak S, Biswas A.K. and Biswas A.B. (2018). Exploring the Bottlenecks: An Assessment of the Implementation Process of Janani Suraksha Yojana in the State of West Bengal, India. International Journal of Medicine and Public Health. 8(1):2933.

16. Mavalankar D. (2019). Maternal Healthcare Financing: Gujarat's Chiranjeevi Scheme and Its Beneficiaries.

17. Rudra S, Gupta I, Joe W. (2010). Demand side financing in health: how far can it address the issue of low utilization in developing countries? Geneva: World Health Organization. World Health report.

18. Rahman M. Ma and Rob U. (n.d) Financial support among poor pregnant women in Bangladesh: an Operational Research Finding.

19. UNICEF DATA. (2019). Maternal health - UNICEF DATA.

20. Victora C.G, Requejo J.H, Barros A.J.D, Berman P, Bhutta Z, Boerma T, Chopra M, de Francisco A, Daelmans B, Hazel E, Lawn J, Maliqi B, Newby H. and Bryce J. (2016). Countdown to 2015: a decade of tracking progress for maternal, newborn, and child survival. The Lancet. 387(10032):2049-2059.

21. Zelalem Ayele D, Belayihun B, Teji K. and Admassu Ayana D. (2014). Factors Affecting Utilization of Maternal Health Care Services in Kombolcha District, Eastern Hararghe Zone, Oromia Regional State, Eastern Ethiopia. International Scholarly Research Notices. 20(14):1-7.
This work is licensed under Creative Commons Attribution 4.0 License
To Submit Your Article Click Here: Submit Manuscript

DOI: $10.31579 / 2768-0487 / 058$
Ready to submit your research? Choose Auctores and benefit from:

$>$ fast, convenient online submission

$>$ rigorous peer review by experienced research in your field

$>$ rapid publication on acceptance

$>$ authors retain copyrights

$>$ unique DOI for all articles

$>$ immediate, unrestricted online access

At Auctores, research is always in progress.

Learn more https://auctoresonline.org/journals/journal-of-clinical-andlaboratory-research 